\title{
Environmental sanitation at Yelikeli, Wardha district - A Survey Study
}

\author{
Research Article
}

\section{Himali G Chandewar ${ }^{1 *}$, Premkumar P Badwaik²}

\author{
1. UG Student, 2. Associate Professor \& HOD, Department of Swasthavritta \\ Mahatma Gandhi Ayurved College Hospital \& Research Centre, Salod (H.), \\ Datta Meghe Institute of Medical Sciences (Deemed to be University) Wardha.
}

\begin{abstract}
Background: Water and sanitation is the most important part of our Environment in all over world. In environmental sanitation the involvement of waste water along with waste disposal which causes harm to our environment. Aim of study: To study regarding Environmental Sanitation at Yelikeli, Wardha district. Method: The data was collected through revalidated Questionnaire then it was analyzed and interpreted. It is allowed the researcher to investigate and understand the current environmental sanitation phenomenon with help of questionnaire at Yelikeli. Result : We observed that 33\% people were going for toilet in open space other than public toilet but after assessment with help of survey it assess that there were near about $66 \%$ people having clean in condition and $30 \%$ people were still dirty condition of sanitation which due to lack of knowledge about environmental sanitation. After the survey we have assessed there were about $60 \%$ people disposed off their waste water from kitchen and bathroom and maintain cleanliness in environment. Conclusion: We conclude with help of survey that most of the villager's are aware about the environmental sanitation and also the villages are more developed as compare to last some decades and villager's having knowledge about the cleanliness of nature is most important for the health of each and everybody.
\end{abstract}

Key Words: Water sanitation, Food sanitation, Excreta disposal, Sewage disposal, Refuse disposal, Environmental sanitation.

\section{Introduction}

The perception of what is clean water and good sanitation evolved over the years. India is still lagging far behind many countries in the field of the environmental sanitation (1).The unsanitary conditions are appealing in India and need a great sanitary awakening similar to what taken place in London in the mid-19th century (2). Improvement in sanitation requires newer strategies and targeted interventions with follow-up evaluation (3). Priorities are particularly important of issue of waste water, environment related health problem, rapid population growth, inequitable distribution of water resources, issue related to administrative problems, urbanization and industrialization, migration and population, rapid economic growth. Environmental sanitation is a major public health issue in India. For proper management of above the environmental sanitation is most important. The population at Yelikeli is denser and there is a mine of stones adjacent to this village. So this village was selected to study the environmental sanitation of it.

Aim

* Corresponding Author:

Premkumar Badwaik

Address- 403, Sahas Iconic, Lunia plots,

Nalwadi,

Nagpur Road,

Wardha. Maharashtra

Email Id: badwaik.prem@gmail.com
To study regarding Environmental Sanitation at Yelikeli, Wardha district

\section{Objectives}

The research has the main objective of examining the causes of the environmental sanitation conditions at the Yelikeli area, its effects on the health of the people and to propose appropriate interventions for improved sanitation in the village.

\section{Material and Methods Material}

Villagers with their families participating and Questionnaires, survey regarding environmental sanitation, Flow charts and integrated messages about environmental sanitation, conduction of workshop on personal hygiene and sanitation promotion.

\section{Methods}

The data was collected through revalidated questionnaire then it was analyzed and interpreted. It was allowed the researcher to investigate and understand the current environmental sanitation with the help of questionnaire at Yelikeli.

\section{Observations and Results}

To understand the exact condition regarding environmental sanitation at Yelikeli with the help perception of villagers, some statistical data mentioned below was analyzed from questionnaires' we had for the villagers. 
Table 1: Age wise distribution of participants

\begin{tabular}{|c|c|c|}
$\begin{array}{c}\text { Age } \\
\text { Group }(\mathbf{y r s})\end{array}$ & No of participants & Percentage \\
\hline $25-34$ yrs & 3 & 10 \\
$35-44$ yrs & 7 & 23.33 \\
\hline $45-54$ yrs & 9 & 30 \\
\hline $55-64$ yrs & 6 & 20 \\
\hline 6 yrs & 5 & 16.67 \\
\hline Total & 30 & 100 \\
\hline Mean \pm SD & $50.06 \pm 14.81$ & \\
& $(25-82$ years $)$ & \\
\hline
\end{tabular}

Graph 1: Age wise distribution of participants

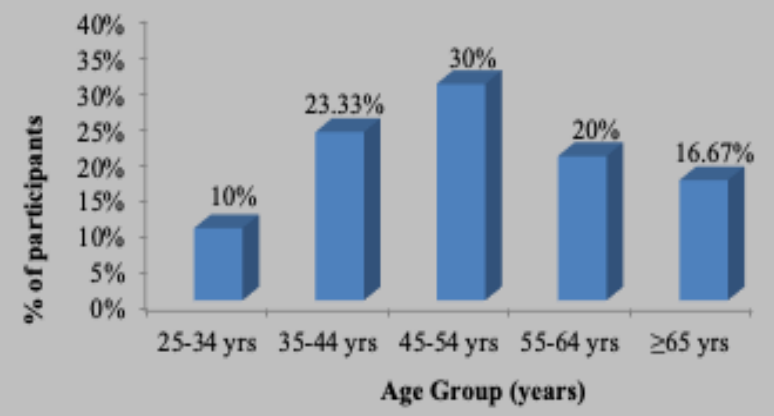

There were maximum $30 \%$ participants from age 45-54 years which gets partly distribution in environmental sanitation in Yelikeli.

Table 2: Toilet facility at house

Toilet Facility No of participants Percentage

\begin{tabular}{|c|c|c|}
\hline Yes & 19 & 63.33 \\
\hline No & 11 & 36.67 \\
\hline Total & 30 & 100 \\
\hline
\end{tabular}

Graph 2: Toilet facility at house

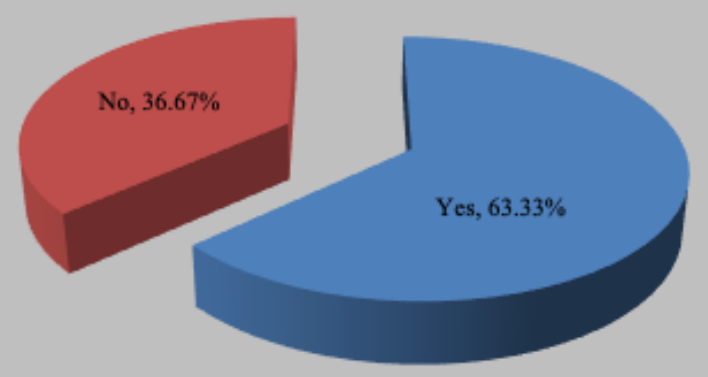

$63.33 \%$ peoples having toilet facility in their houses and remaining $36.67 \%$ peoples having not such type of toilet facilities in their houses.

Table 3: Toilet going places

\section{Toilet}

Public Toilet

In the bush

In the gutter

Other

Total

\section{No of participants}

\begin{tabular}{|c|c|}
\hline articipants & Percentage \\
\hline 19 & 63.33 \\
\hline 11 & 33.67 \\
0 & 0 \\
\hline 0 & 0 \\
\hline 30 & 100 \\
\hline
\end{tabular}

\section{Graph 3: Toilet going places}

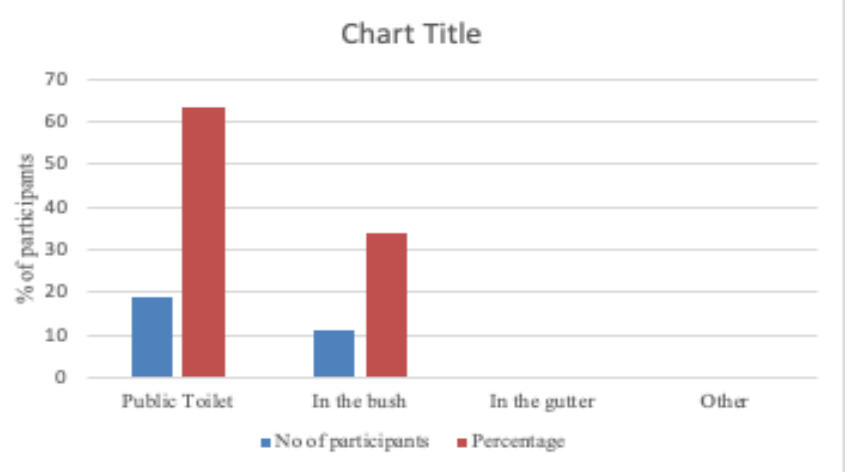

$63.33 \%$ peoples were going in public toilet and $33.67 \%$ peoples were going in the bush.

Table 4: The distance from house to the nearest toilet facility

\begin{tabular}{|c|c|c|}
\hline Distance & No of participants & Percentage \\
\hline Less than 100 meters & 19 & 63.33 \\
\hline $100-250$ meters & 1 & 3.33 \\
\hline $250-400$ meters & 9 & 30 \\
\hline$>400$ meters & 1 & 3.33 \\
\hline Total & 30 & 100 \\
\hline
\end{tabular}

\section{Graph 4: The distance from house to the nearest} toilet facility

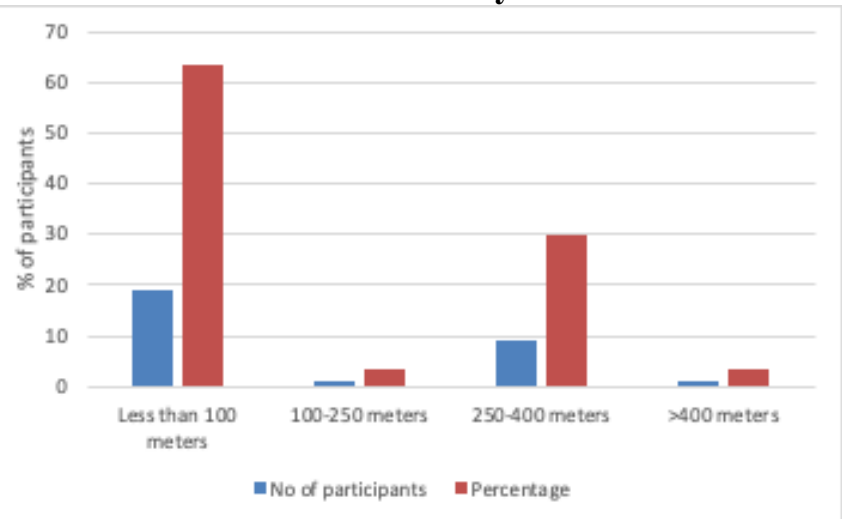

$63.33 \%$ peoples have less than 100 meters from house to nearest toilet facility.

Table 5: Pay for the service

\begin{tabular}{|c|c|c|}
\hline Pay for service & No of participants & Percentage \\
Yes & 2 & 6.67 \\
No & 28 & 93.33 \\
\hline Total & 30 & 100 \\
\hline
\end{tabular}

Graph 5: Pay for the service

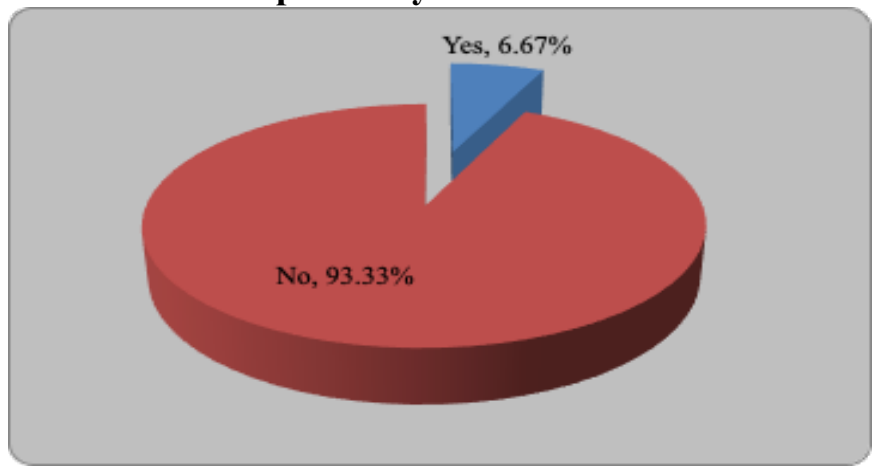

93.33\% peoples did not pay any money for service regarding environmental sanitation. 
Table 6: Assessment of the condition of the whole family

\section{Condition of the} family

Very clean

Clean

Dirty

Very Dirty

Waste Water

Total

No
partic
1
20
9
0
0
30

No of ticipants

\begin{tabular}{|c|c|}
\hline 1 & 3.33 \\
\hline 20 & 66.67 \\
\hline 9 & 30 \\
\hline 0 & 0 \\
\hline 0 & 0 \\
\hline 30 & 100 \\
\hline
\end{tabular}

Graph 6: Assessment of the condition of the whole family

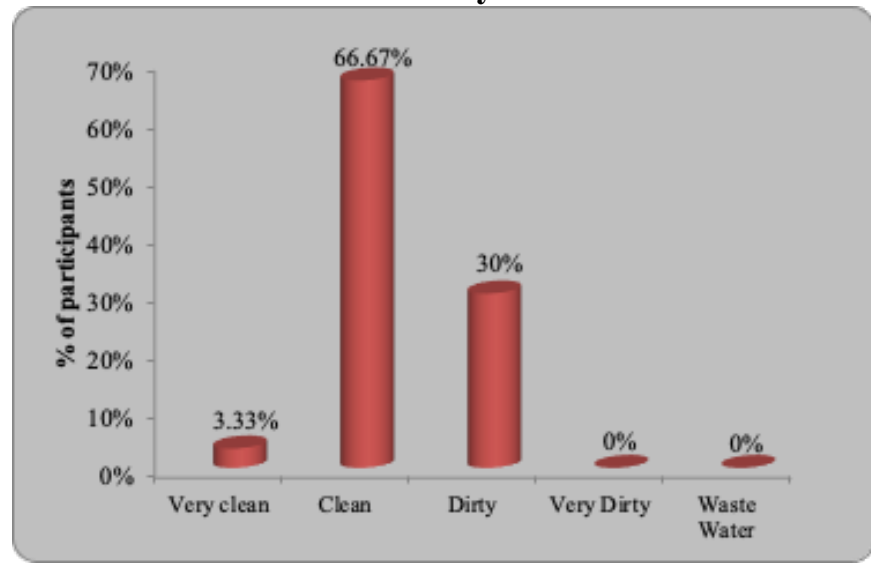

$66.67 \%$ participants was observed as clean condition of their families during survey.

Table 7: Drainage pipes from house

\begin{tabular}{|c|c|c|}
$\begin{array}{c}\text { Gutters from } \\
\text { your house }\end{array}$ & $\begin{array}{c}\text { No of } \\
\text { participants }\end{array}$ & Percentage \\
\hline Yes & 11 & 36.67 \\
No & 19 & 63.33 \\
\hline Total & 30 & 100 \\
\hline
\end{tabular}

Graph 7: Drainage pipes from house

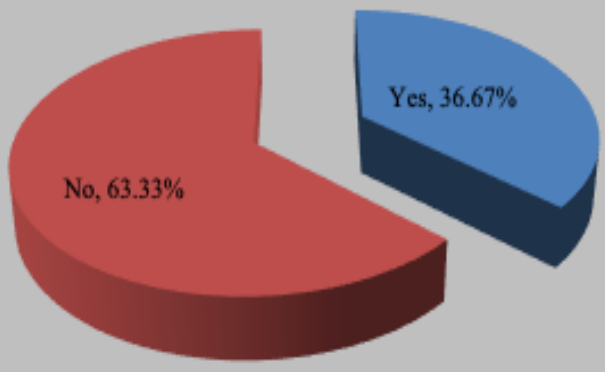

Table 8: Disposal of waste water from your kitchen and bathroom

\section{Waste water}

from kitchen and No of patients bathroom

In the open space In a covered pit

Other

Total

\begin{tabular}{|c|c|}
\hline 0 & 0 \\
\hline 18 & 60 \\
\hline 1 & 3.33 \\
\hline 19 & 63.33 \\
\hline
\end{tabular}

Graph 8: Disposal of waste water from your kitchen and bathroom

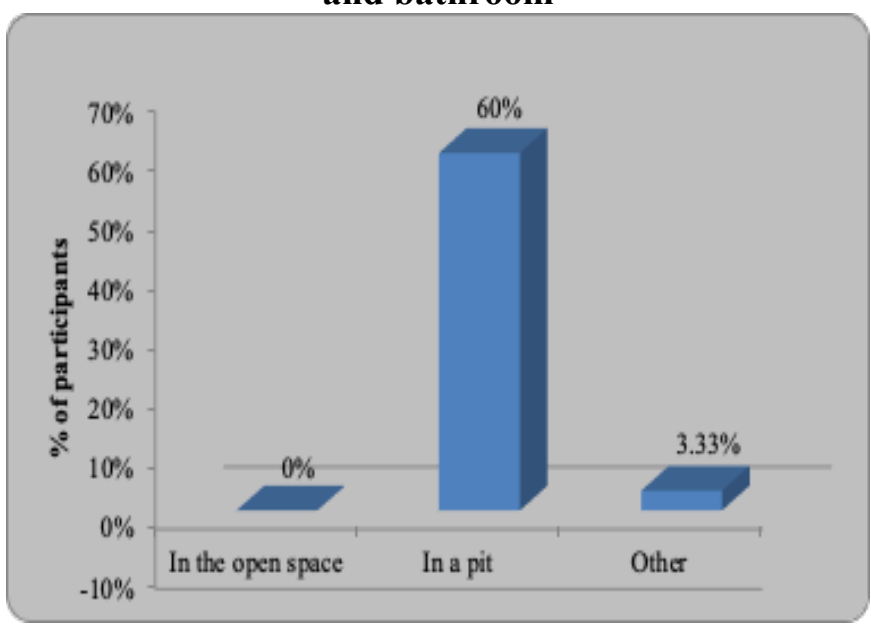

$60 \%$ peoples were disposed their waste water from kitchen and bathroom in Pit.

Table 9: Assessment of the environmental sanitation condition in neighbourhood

\begin{tabular}{c|c|c|}
$\begin{array}{c}\text { Environmental } \\
\text { sanitation } \\
\text { condition }\end{array}$ & $\begin{array}{c}\text { No of } \\
\text { participants }\end{array}$ & Percentage \\
\hline Very Good & 0 & 0 \\
Good & 19 & 63.33 \\
\hline Bad & 10 & 33.33 \\
\hline Very Bad & 1 & 3.33 \\
Total & 30 & 100 \\
\hline
\end{tabular}

Graph 9: Assessment of the environmental sanitation condition in neighbourhood

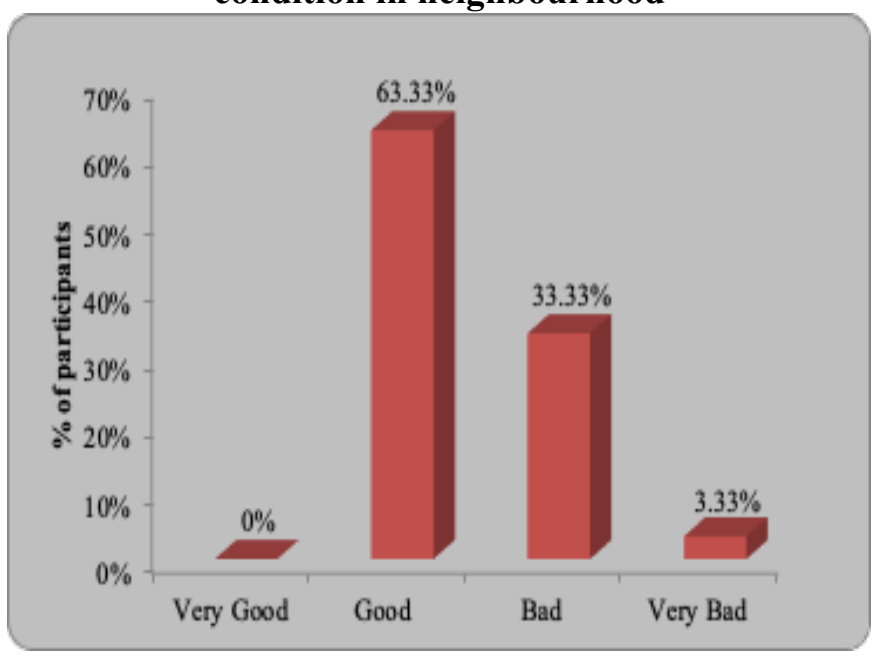

Table 10: Different ways to dispose off wet $\&$ dry waste/ refuse

\begin{tabular}{|c|c|c|}
\hline Waste/Refuse & No of patients & Percentage \\
\hline House to house & 0 & 0 \\
\hline Burnt & 14 & 46.67 \\
\hline In a covered pit & 13 & 43.33 \\
\hline $\begin{array}{c}\text { In an open space } \\
\text { Community waste } \\
\text { disposal site }\end{array}$ & 3 & 10 \\
\hline $\begin{array}{c}\text { Other } \\
\text { Total }\end{array}$ & 0 & 0 \\
\hline
\end{tabular}


Graph 10: Different ways to dispose off wet \& dry waste/ refuse

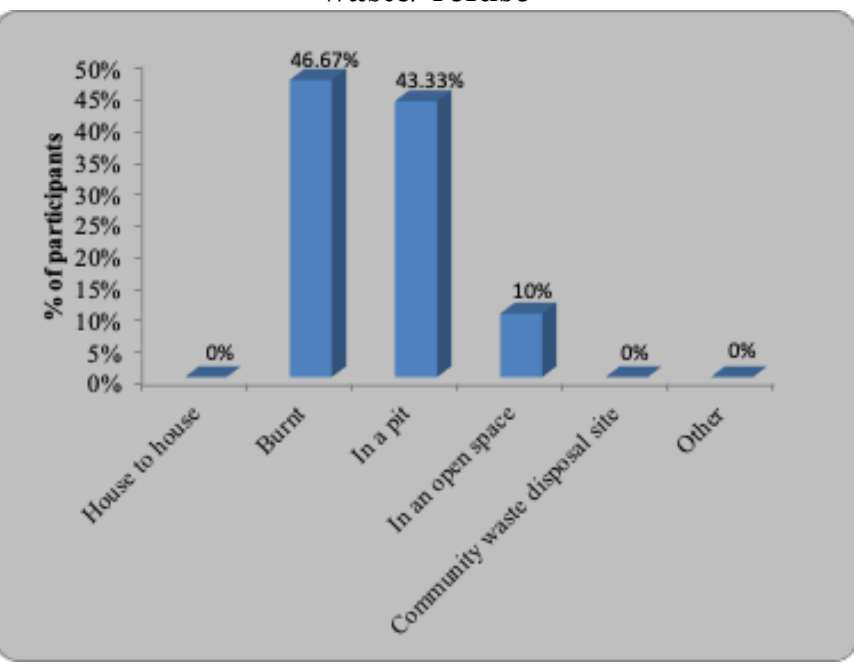

$46.67 \%$ people burnt their Waste and $43.33 \%$ peoples dispose their waste in a covered pit so that grampanchayat workers would collect and disposed off properly as per Government norms and rest $10 \%$ peoples disposed waste in open space.

Table 11: Government should enforce the by - laws to make every individual responsible for the environmental sanitation

\begin{tabular}{|c|c|c|}
$\begin{array}{c}\text { Environmental } \\
\text { sanitation }\end{array}$ & No of patients & Percentage \\
\hline Yes & 29 & 96.67 \\
\hline No & 1 & 3.33 \\
\hline Total & 30 & 100 \\
\hline
\end{tabular}

Graph 11: Government should enforce the by-laws to make every individual responsible for the environmental sanitation?

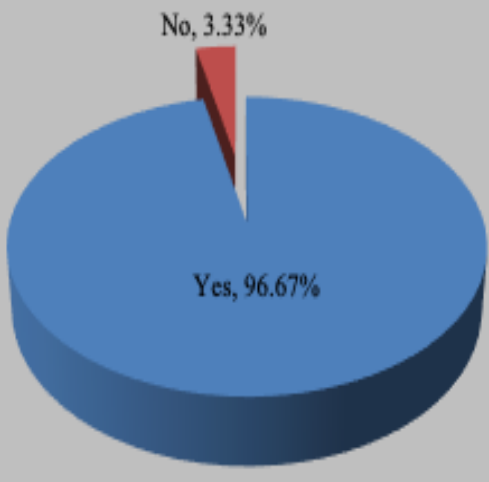

Table 12: General opinion about environmental sanitation in Yelikeli?

\begin{tabular}{|c|c|c|}
\hline $\begin{array}{c}\text { Environmental } \\
\text { sanitation }\end{array}$ & No of patients & Percentage \\
\hline Very clean & 4 & 13.33 \\
\hline Clean & 20 & 66.67 \\
\hline Dirty & 6 & 20 \\
Very Dirty & 0 & 0 \\
\hline Total & 30 & 100 \\
\hline
\end{tabular}

Graph 12: General opinion about environmental sanitation in Yelikeli?

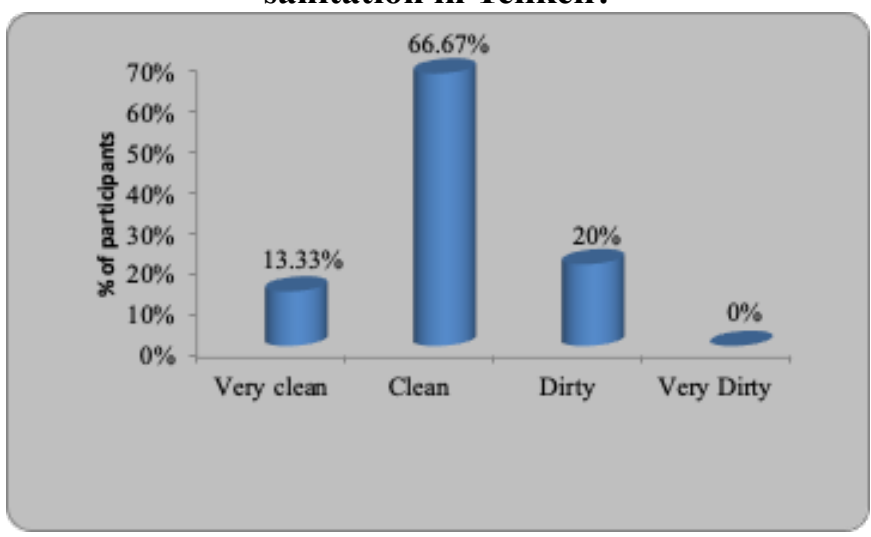

$66.66 \%$ people thought that clean environmental sanitation.

\section{Discussion}

As per the survey done at village Yelikeli regarding the awareness about environmental sanitation, we have discussed all their certain problems and has given them assurance regarding their problems. On the basis of this survey study, we have analyzed that - there are about 33\% people are go for toilet in open space other than public toilet but after assessment with help of survey it assess that there are near about $66 \%$ people having clean in condition and $30 \%$ people are still dirty condition of sanitation which due to lack of knowledge about environmental sanitation (3). Also after the survey we had assessed there were about $60 \%$ people disposed off their waste water from kitchen and bathroom and maintain cleanliness in environment. There were near about $96 \%$ people who think that government should enforce by law to make every individual responsible for the environmental sanitation (4). After done of whole survey we could assessed and analyzed that at village Yelikeli there were $66 \%$ people having general opinion about environmental sanitation should be clean.

The main problem seems to be related to the insufficient awareness of people living in unsanitary conditions and of their national and local authorities, and the costs of implementation, operation and maintenance of the systems (5).

Strategies to improve environmental sanitation sanitation is most important as a whole, including improvement of facilities, environmental conditions and behavioral change related environmental sanitation; Also sanitation programmes take which based and the community should be fully involved in the process (6); Environmental sanitation should be a component of other health-promoting or disease control programmes (7); Awareness regarding environmental sanitation needs to be raised and sanitation set as a priority in village Yelikeli.

\section{Conclusion}

We had concluded by this survey that the most of the villagers were aware about the environmental sanitation and also the villages were more developed as compare to last some decades and villagers having knowledge about the cleanliness of nature is most 
important for the health of each and everybody. They thought that conservation and preserving of environment from various hazards and make pollution free environment for our present and also for our future. Most of people had put their point of view regarding sanitation and aware other villagers regarding the public sanitation.

\section{References}

1. Pandve HT Environmental sanitation: An ignored issue in India. Indian J Occup Environ Med 2008; 12:40.

2. Majra JP, Gur A .India needs a great sanitary awakening. Indian J Occup Environ Med 2008; 12: 143.
3. Kumar SG, Jaya Rama S. Issues related to sanitation failure in India and future perspective. Indian J Occup Environ Med 2009; 13: 104.

4. Wright AM, Toward a strategic sanitation approach, UNEP-World Bank Water and Sanitation program. International Bank for Reconstruction/ The World Bank, Washington, 1997;1-41.

5. UNICEF.UNICEF Strategies in water and environmental sanitation. New York, 1995; 63.

6. WHO/Environmental sanitation collaborative Council, Sanitation Promotion. World Health Organization, Working Group on Promotion of Sanitation, Geneva, 1998 (WHO/EOS/98.5), 277.

7. World Health Organization, PHAST step-by-step guide: a participatory approach for the control of diarrhoeal disease WHO, Geneva, 1998, (WHO/ EOS/98.3); 134. 